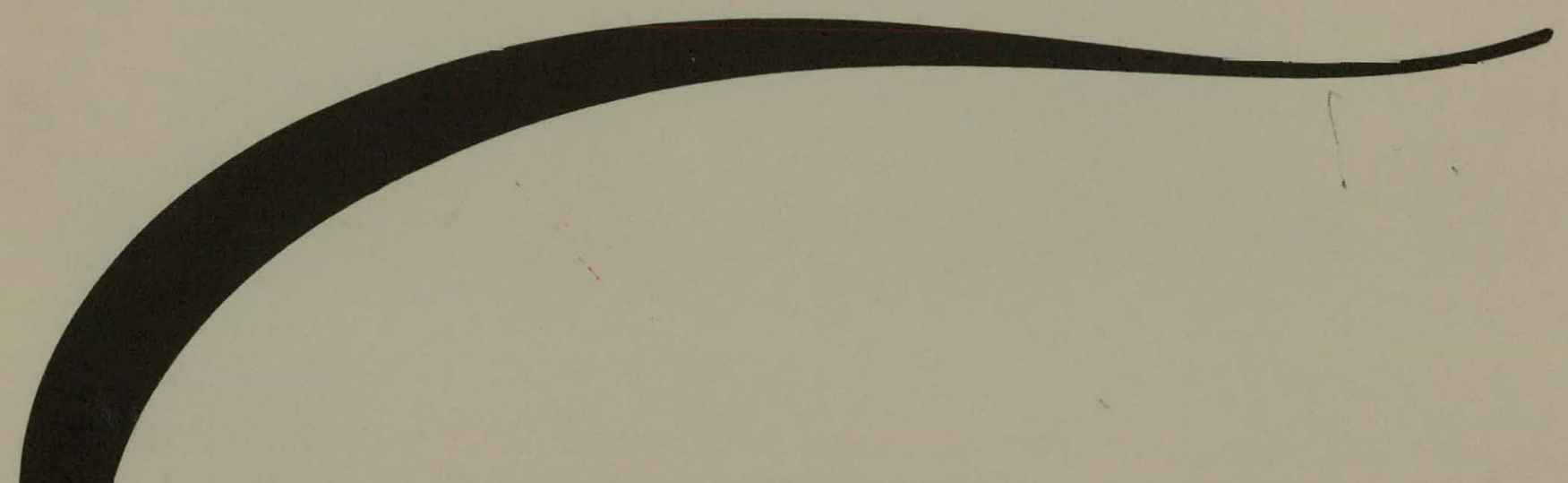

GENERALIZED AREA OF INTERSECTION MODEL FOR URANYL NITRATE FILLED PIPE INTERSECTIONS

\title{
Deanne Dickinson
}

C. L. Schuske

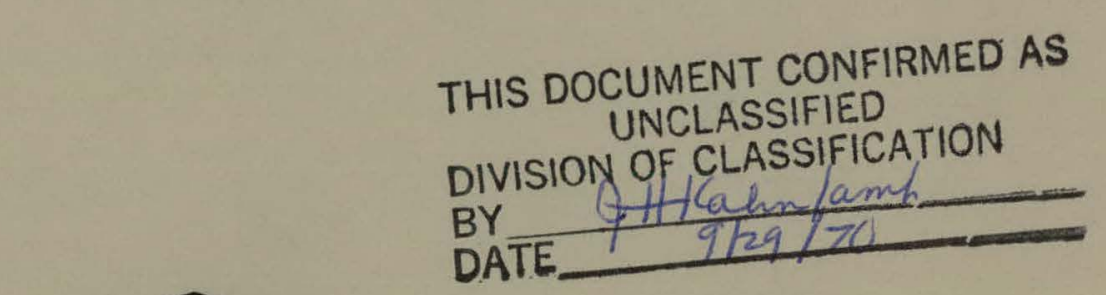

\section{Dow}

(A)

THE DOW CHEMICAL COMPANY

ROCKY FLATS DIVISION

P. O. BOX 888

GOLDEN, COLORADO 80401

U.S. ATOMIC ENERGY COMMISSION

CONTRACT AT(29-1)-1106 


\section{DISCLAIMER}

This report was prepared as an account of work sponsored by an agency of the United States Government. Neither the United States Government nor any agency Thereof, nor any of their employees, makes any warranty, express or implied, or assumes any legal liability or responsibility for the accuracy, completeness, or usefulness of any information, apparatus, product, or process disclosed, or represents that its use would not infringe privately owned rights. Reference herein to any specific commercial product, process, or service by trade name, trademark, manufacturer, or otherwise does not necessarily constitute or imply its endorsement, recommendation, or favoring by the United States Government or any agency thereof. The views and opinions of authors expressed herein do not necessarily state or reflect those of the United States Government or any agency thereof. 


\section{DISCLAIMER}

Portions of this document may be illegible in electronic image products. Images are produced from the best available original document. 


\section{LEGAL NOTICE}

This report was prepared as an account of Government sponsored work. Neither the United States, nor the Commission, nor any person acting on behalf of the Commission:

A. Makes any warranty or representation, expressed or implied, with respect to the accuracy, completeness, or usefulness of the information contained in this report, or that the use of any information, apparatus, method, or process disclosed in this report may not infringe privately owned rights; or

B. Assumes any liabilities with respect to the use of, or for damages resulting from the use of any information, apparatus, method, or process disclosed in this report.

As used in the above, "person acting on behalf of the Commission" includes any employee or contractor of the Commission, or employee of such contractor, to the extent that such employee or contractor of the Commission, or employee of such contractor prepares, disseminates, or provides access to, any information pursuant to his employment or contract with the Commission, or his employment with such contractor.

Printed in the United States of America

Available from

Clearinghouse for Federal Scientific and Technical Information

National Bureau of Standards, U. S. Department of Commerce

Springfield, Virginia 22151

Price: Printed Copy $\$ 3.00$; Microfiche $\$ 0.65$ 


\title{
GENERALIZED AREA OF INTERSECTION MODEL. FOR URANYL NITRATE FILLED PIPE INTERSECTIONS
}

Deanne Dickinson

C. L. Schuske

\author{
THE DOW CHEMICAL COMPANY \\ ROCKY FLATS DIVISION \\ P. O. BOX 888 \\ GOLDEN, COLORADO 80401 \\ Prepared under Contract AT(29-1)-1106 \\ for the \\ Albuquerque Operations Office \\ U. S. Atomic Energy Commission
}


RFP-1553 


\title{
CONTENTS
}

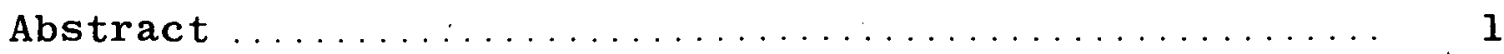

Definitions $\ldots \ldots \ldots \ldots \ldots \ldots \ldots \ldots \ldots \ldots \ldots \ldots \ldots \ldots \ldots \ldots \ldots \ldots \ldots$

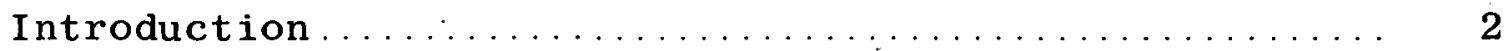

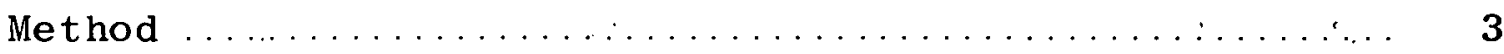

Effect of Additional Coiumns ........... 8
\end{abstract}

Rules Defining the

Generalized Area of Intersection Model .......... 9

Examples of Use of the

Generalized Area of Intersection Model ........... 11

Comparison of Generalized Area of Intersection

Model ánd Generalized Equivalent Cylinder Model .... 13

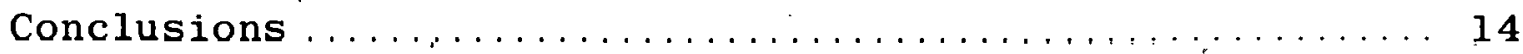


RFP-1553 
GENERALIZED AREA OF INTERSECTION MODEL FOR

URANYL NITRATE FILLED PIPE INTERSECTIONS

Deanne Dickinson and C. L. Schuske

Abstract. An empirical model is presented for calculating safe nuclear criticality parameters for complex arrays of intersecting pipes containing enriched uranyl nitrate solution.

The current model, an extension of one presented in a previous report, is derived from Monte Carlo calculations as well as from experimental data.

\section{DEF IN IT IONS}

Diameter: Always the inner diameter of a pipe.

Column (Central Column): The main column or pipe from which branching of arms occurs; the largest diameter pipe.

Arm: Any pipe or cylinder intersecting the central column.

Intersection Area: The area of intersection of an arm with the tangent plane of the column at the point where the axis of the arm intersects the column. [See Figure 1, where $\mathrm{D}=$ diameter, theta $(\theta)$ = angle between arm axis and column axis, and $A=$ area of intersection. ]

Sector: Any 18-inch length of the central column. (See Figure 2.) Quadrant: One-fourth of a sector; the sector is divided into four quadrants by two perpendicular planes intersecting along the axis of the sector. (See Figure 2.)

Minimal Reflection: The reflection from the $\sim 1 / 8$-inch thick steel walls of the pipes only.

Nominal Reflection: Reflection from 1/8-inch thick steel walls of the pipe plus $1 / 2-i n c h$ of water reflector (or an equivalent amount. of reflection) around the pipes. 


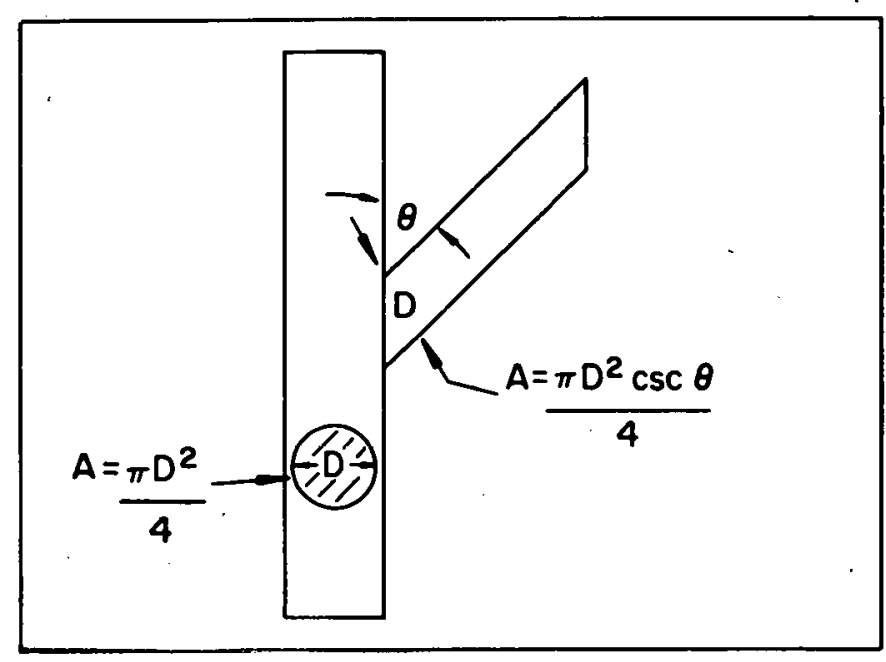

FIGURE 1. Surface area in contact with central column.

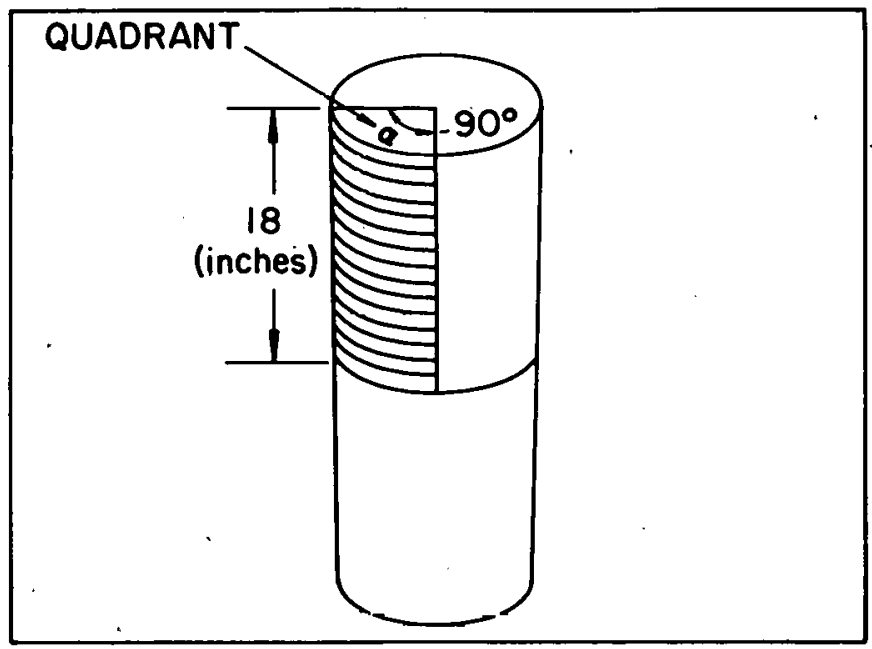

FIGURE 2. Sector and quadrant definttions.

Full Reflection: Reflection resulting from full water flooding of a pipe system (pipes have 1/8-inch thick steel walls); safe dimensions are calculated by reducing all diameters in the minimal cases by a factor of $0.635 .^{1}$

\section{INTRODUCT ION}

Sufficient experimental and computational data now exist ${ }^{2,3}$ to solve a wide variety of problems concerned w1th uranyl nitrate filled pipe intersections.

The empirical model presented lil his paper was derived from these data. The purpose of the model is to facilitate rapid analysis of pipe intersection problems commonly found in the fissile process plant. The model uses as a critical parameter the area of inter-

${ }^{1}$ B. B. Ernst and C. L. Schuske. Empirical Method for Calculating Pipe Intersections Containing Fissile Solutions. RFP-1197. Rocky Flats Division, The Dow Chemical Company, Golden, Colorado. September 9, 1968 .

Ibid.

${ }^{3}$ Deanne Dickinson. Calculations for Pipe Intersections Containing Fissile Solution. RFP-1499. Rocky Flats Division, The Dow Chemical Company, Golden, Colorado. June 24, 1970. 
section of the arms (pipes) with the central column. This model hereafter will be referred to as the GAI (Generalized Area of Intersection) model.

The original $\mathrm{AI}^{4}$ (Area of Intersection) model was primarily designed to handle complex intersection problems with an appropriate margin of safety. However, when applied to simple intersections such as $T^{\prime} ' s$ and crosses, the AI model is overly conservative: The GAI model, on the other hand, calculates both simple and complex intersections with adequate but not over conservatism. The AI model limits the area of intersection per quadrant of arms with the central column, regardless of whether or not the other quadrants in the sector actually contain arms. The GAI model provides different limits on the intersection area and column size depending on the number of quadrants which contain arms. The GAI model and the Generalized Equivalent Cylinder (GEC) model, described in RFP-1499, are alternate methods. A comparison of the two models is presented.

\section{METHOD}

The general method used to derive the GAI model was first to select arbitrarily a central column diameter and then to calculate critical arm diameters for the following cases: (1) the simple repeating $T$ (one quadrant per sector as shown in Figure 3), and (2) two quadrants per sector [Figures 4 (a) and (b)]. The cases for 3 and 4 quadrants per sector (Figure 5) are combined and are handled as previously presented in RFP-1197. Safe ruìes and criteria are developed from these critical cases by reducing the central column diameter and arm diameters by 10 to 15 percent. The rules and criteria for nominal and full reflected systems are developed as in RFP-1197 by adding reflector savings to the minimal reflected cases (see section on Definitions). The data used in arriving at the rules

\footnotetext{
${ }^{4}$ RFP-1197. Loc.cit.
} 


\section{RFP-1553}

and criteria are given in Table $I$. All keff calculations were performed by the O5R Monte Carlo code. 5 The assumptions used in the derivation of the GAI model were justified in RFP-1197 and RFP-1499.

${ }^{5}$ D. C. Irving, R. M. Freestone, Jr., and F. B. K. Kam. O5R, A General-Purpose Monte Carlo Neutron Transport Code. ORNL-3 $\overline{622}$. Union Carbide Corporation, Oak Ridge National Laboratory, Oak Ridge, Tennessee. February, 1965.

FIGURE 3. Six layer 'T-intersection (one quadrant containing arms).

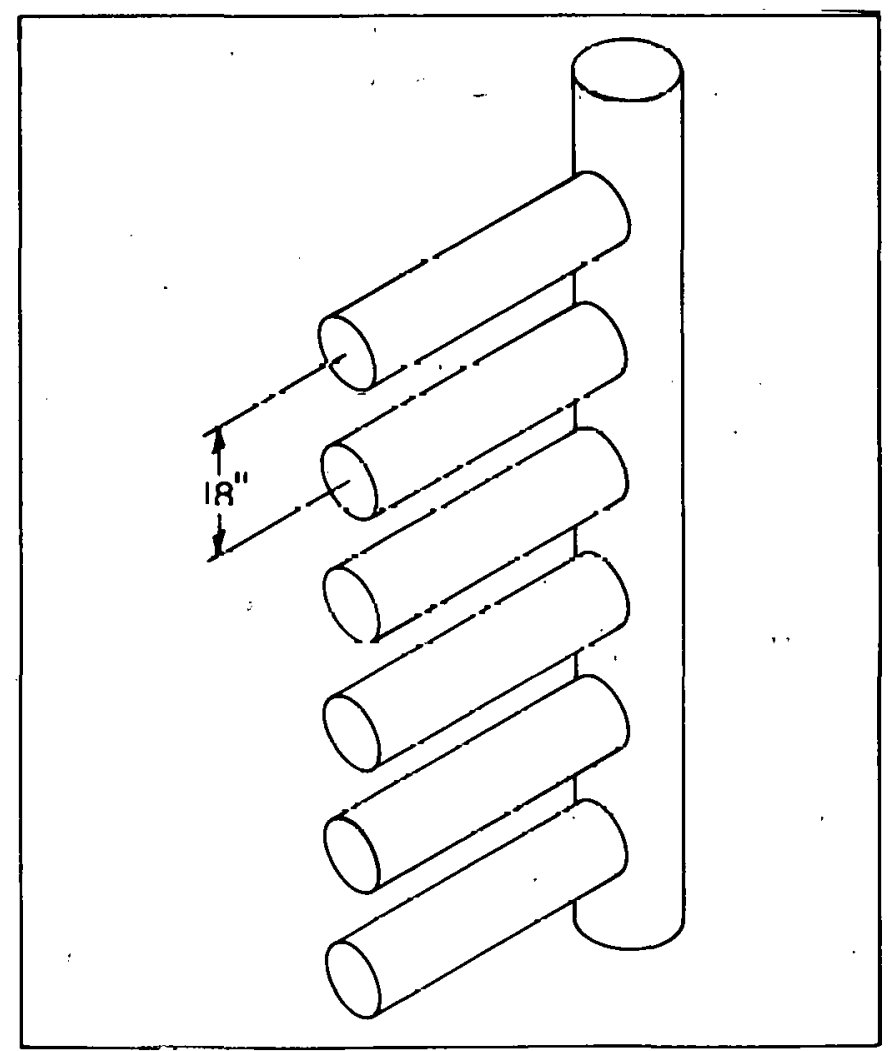



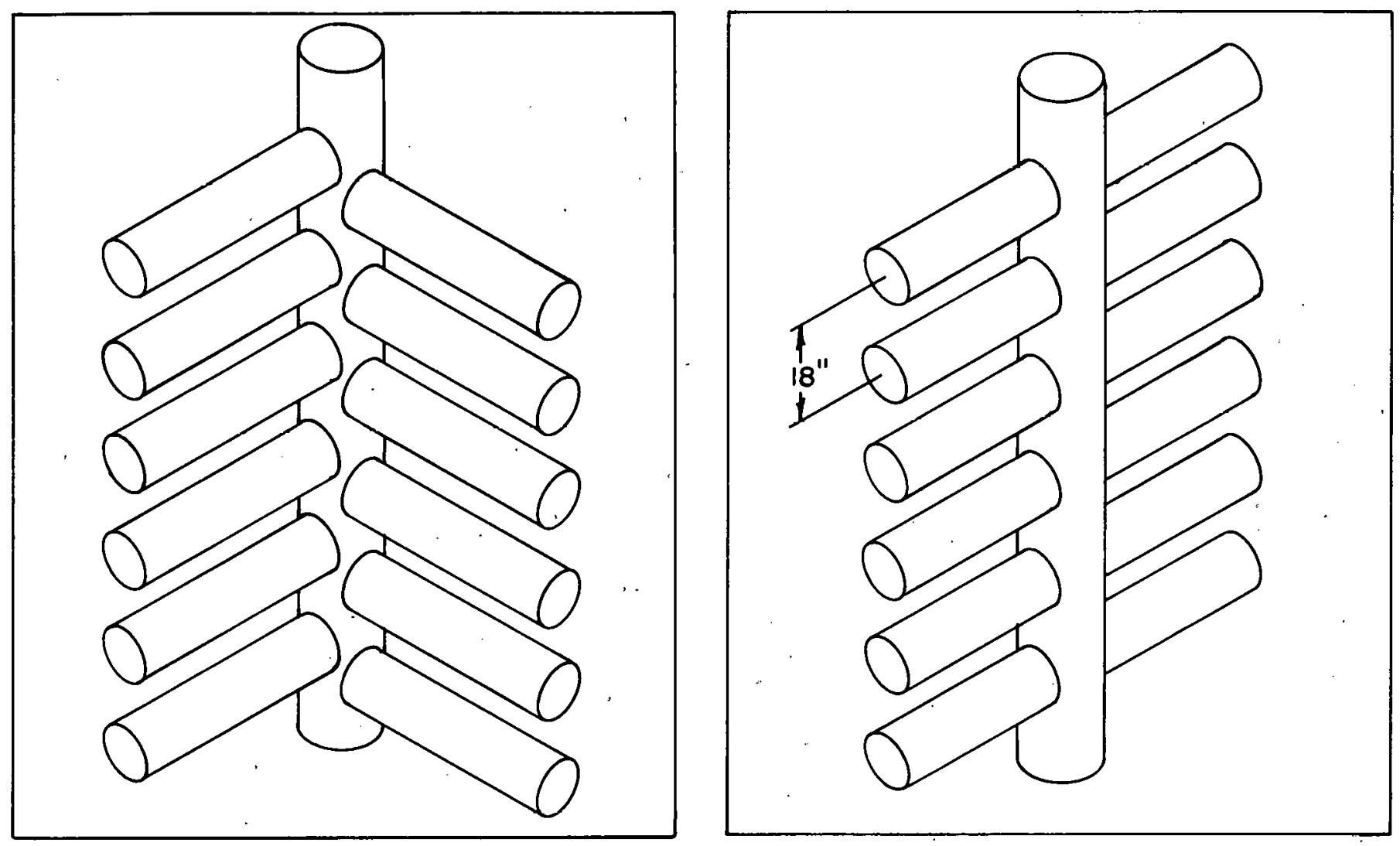

FIGURES 4 (a) AND (b). Six layer intersection with two quadrants containing arms: (a) arms at $90^{\circ}$ to each other, and (b) arms at $180^{\circ}$ to each other. 


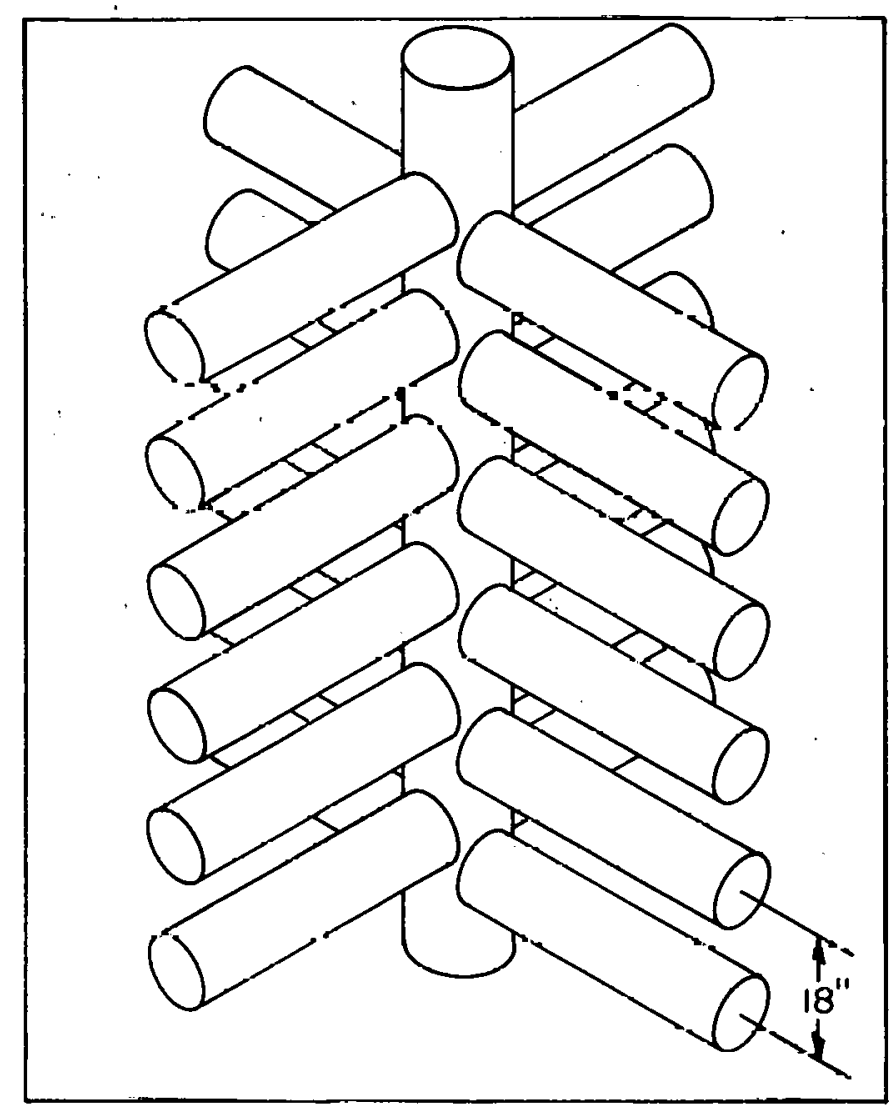

FIGURE 5. Six layer intersection with four quadrants containing arms: 
TABLE I. Calculations for GAI model for uranyl nitrate solution.

\begin{tabular}{|c|c|c|c|c|c|c|c|}
\hline \multirow{2}{*}{$\begin{array}{l}\text { Number of } \\
\text { Quadrants } \\
\text { Containing } \\
\text { Arms }\end{array}$} & \multirow[b]{2}{*}{$\begin{array}{l}\text { Figure } \\
\text { Reference }\end{array}$} & \multicolumn{3}{|c|}{ Near Critical Dimensions } & \multicolumn{3}{|c|}{ Safe Dimensions } \\
\hline & & $\begin{array}{c}\text { Column } \\
\text { Diameter } \\
\text { (inches) }\end{array}$ & $\begin{array}{c}\text { Arm } \\
\text { Diameter } \\
\text { (inches) }\end{array}$ & $k_{\text {eff }} \pm \sigma$ & $\begin{array}{l}\text { Column } \\
\text { Diameter } \\
\text { (inches) }\end{array}$ & $\begin{array}{c}\text { Arm } \\
\text { Diameter } \\
\text { (inches) }\end{array}$ & $k_{e f f} \pm \sigma$ \\
\hline 1 & 3 & 8.5 & 8.5 & $0.982 \pm 0.014$ & 7.25 & 7.25 & $0.864 \pm 0.019$ \\
\hline 2 & $4(b)$ & --- & --- & --- & 7.0 & 6.15 & $0.815 \pm 0.013$ \\
\hline 4 & 5 & --- & --- & --- & 6.5 & 5.5 & $0.852 \pm 0.015$ \\
\hline
\end{tabular}

NOTE: Solution is 451 grams per liter uranyl nitrate; the uranium is enriched to 93 percent by weight uranium 235 .

In all cases the intersection was repeated six times. All pipe walls are 1/8-inch thick. 
RFP-1553

Effect of Additional Columns: Previous models have all been limited to the case of a single central column, leaving it up to the user to decide when a second column is sufficiently far away to be considered isolated. Monte Carlo calculations were performed to determine the effect of adding a second column to each of two intersections, one near critical, the second safe. For the first case, a second column was added to a near-critical cross intersection (see Figure 6). The

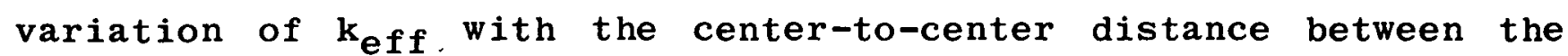
columns is shown in Table. II. Since the increase in $k_{e f f}$ resulting from a second column at a separation of two feet was less than one standard error, the two foot distance was selected as the minimum separation permitted by the GAI model. Then a calculation was performed on a safe s1x-1ayer cruss intersection to dotermine the change in $k_{e f f}$ produced on a far subcritical intersection by a second column; the resulting increase in $k_{\text {eff }}$ was only 0.002 (from $0.815 \pm 0.013$ to $0.817 \pm 0.016)$, which is negligible when compared to the standard errors involved. Because of the smallness of the change produced by adding a second column, it is inferred that a third column would also produce an acceptably small change in $k_{e f f}$, although no calculations were done to study the effect of a third column. An example (see Example 2) is presented of a system containing three interconnected columns, and an OББR caloulation verified that the diduleris and separations calculated by the GAI model are safe.

TABLE TI. Change in keff resulting from the addition of a second column for a nearcritical cross intersection (see Figure 6).

\begin{tabular}{|c|c|c|}
\hline $\begin{array}{c}\text { Number } \\
\text { of } \\
\text { Columns }\end{array}$ & $\begin{array}{c}\text { Center-to-Center } \\
\text { Separation of Columns } \\
\text { (inches) }\end{array}$ & $k_{\text {eff }} \pm \sigma$ \\
\hline 1 & -- & $0.989 \pm 0.010$ \\
2 & 24 & $0.993 \pm 0.015$ \\
2 & 18 & $1.010 \pm 0.014$ \\
\hline
\end{tabular}




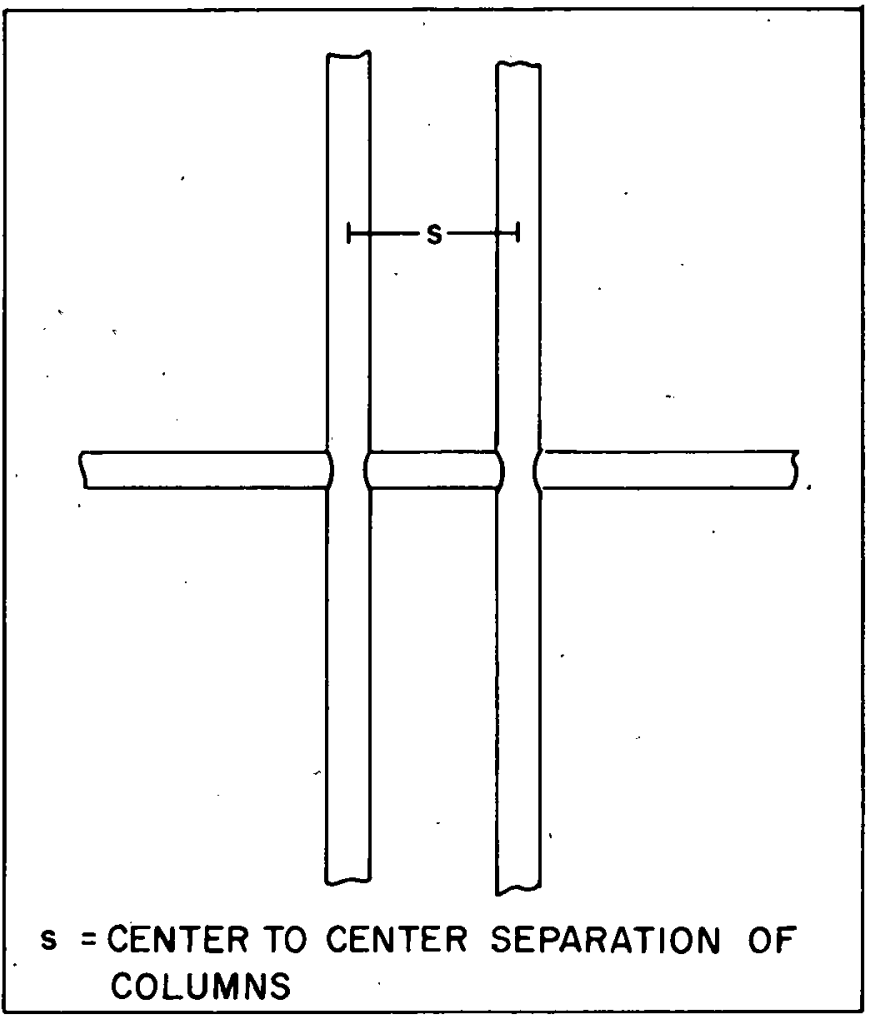

FIGURE 6. Cross intersection with second column added.

\section{RULES DEFINING THE GAI MODEL}

1. The area of intersection of the arms with the column must be calculated for all quadrants containing arms, and the calculated area must not exceed the maximum value given in Table III for the appropriate number of quadrants used and the reflection condition. The intersection area must be distributed in such a way that it is impossible to find any quadrant which contains more area than that permitted by Table III.

2. The central column diameter must not be greater than the appropriate limiting value given in Table III.

3. A maximum of three columns is permitted, and the center-to-center distance between any pair of columns must be at least two feet

4. For the case of nominal or full reflection, a maximum of four arms per quadrant is permitted. There is no limitation on the number of arms per quadrant in the case of minimal reflection. 
TABLE III. Maximum intersection areas and column diameters permitted by the GAI model.

\begin{tabular}{|c|c|c|c|c|c|c|}
\hline \multirow[b]{2}{*}{$\begin{array}{l}\text { Number of } \\
\text { Quadrants } \\
\text { Containing } \\
\text { Arms in a } \\
\text { Sector }\end{array}$} & \multicolumn{2}{|c|}{ Minimal Reflection } & \multicolumn{2}{|c|}{ Nominal Reflection } & \multicolumn{2}{|c|}{ Full Reflection } \\
\hline & $\begin{array}{c}\text { Maximum } \\
\text { Central } \\
\text { Column } \\
\text { Diameter } \\
\text { (inches) }\end{array}$ & $\begin{array}{c}\text { Maximum } \\
\text { Intersection } \\
\text { Area Per } \\
\text { Quadrart } \\
\text { (square ir_ches) }\end{array}$ & $\begin{array}{l}\text { Maximum } \\
\text { Central } \\
\text { Column } \\
\text { Diameter } \\
\text { (inches) }\end{array}$ & $\begin{array}{c}\text { Maximum } \\
\text { Intersection } \\
\text { Area Per } \\
\text { Quadrant } \\
\text { (square inches) }\end{array}$ & $\begin{array}{l}\text { Maximum } \\
\text { Central } \\
\text { Column } \\
\text { Diameter } \\
\text { (inches) }\end{array}$ & $\begin{array}{c}\text { Maximum } \\
\text { Intersection } \\
\text { Area Per } \\
\text { Quadrant } \\
\text { (square inches) }\end{array}$ \\
\hline 2 & 7.00 & 29.70 & 6.00 & 20.83 & 4.44 & 11.98 \\
\hline 3 or 4 & 6.50 & 23.75 & 5.50 & $16.0 \mathrm{C}$ & 4.12 & 9.60 \\
\hline
\end{tabular}


EXAMPLES OF USE OF THE GAI MODEL

The following examples illustrate the application of the GAI model. In each case, the goal is to maximize pipe diameters and minimize spacings. All pipes are assumed to be filled with enriched (93 percent by weight $\mathrm{U}^{235}$ ) uranyl nitrate solution at a concentration of 450 grams per liter of uranium, and minimal reflection is assumed.

Example 1 (see Figure 7): Note that arms 1 through 6, all of diameter $\mathrm{d}_{2}$, must be placed in the same sector. Assume that the separation, $s$, is large enough to put arms 7 through 10, all of diameter $d_{3}$, in a separate sector. For the first sector (arms 1 through 6), only two quadrants contain arms, and hence each quadrant is permitted 29.7 square inches of intersection area, giving

$$
\mathrm{d}_{2}=\sqrt{\frac{4}{\pi}\left(\frac{29.7}{3}\right)}=3.55 \text { inches }
$$

For the sector containing arms 7 through 10, the four quadrants are used, and hence $d_{1}$, the column diameter, is 6.5 inches, and $d_{3}=5.5$ inches.

Finally, the separation, $s$, must be chosen large enough so that no quadrant contains more intersection area than permitted by Table III. This is accomplished by setting $s=18-3.55$ inches $=14.45$ inches. By comparison, the maximum arm diameters permitted by the GEC model for a 6.5-inch column are $d_{2}=3.72$ inches and $d_{3}=5.02$ inches.

Example 2 (see Figure 8): Consider first the spacing of the columns, since that is independent of arm or column diameters. The distances $s_{1}$ and $s_{2}$ must each be 24 inches; then the distance between columns 1 and 3 is $24 \sqrt{2}$ inches.

For column 1, there is only one sector to consider, and it has two quadrants containing arms. Therefore, column 1 may have a diameter of 7.0 inches, and each quadrant may contain 29.7 square inches of intersection area; thus; arm 2 may have a diameter of 6.15 inches and arm 1, which is at $45^{\circ}$, a diameter of 5.17 inches. Note that the diameter of arm 2, which also intersects column 2, may have to be reduced in order to make column 2 safe. 


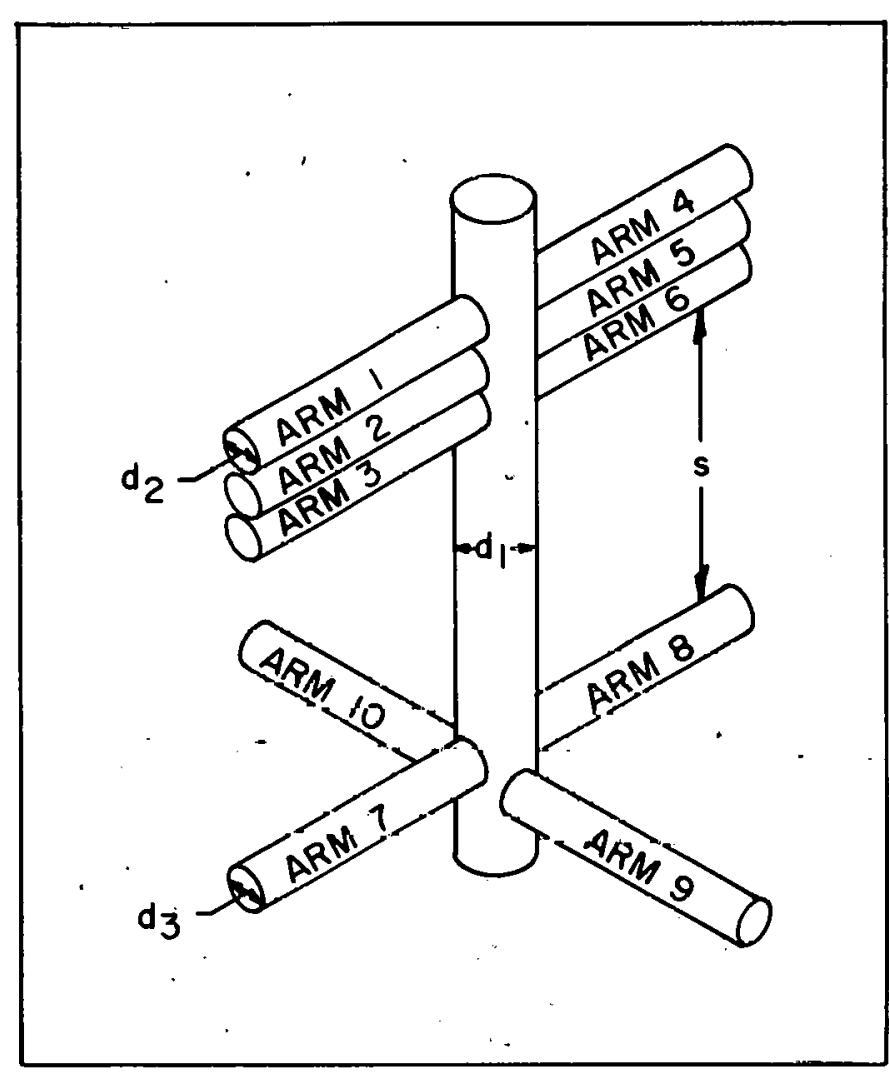

FIGURE 7. Geometry for Example 1.

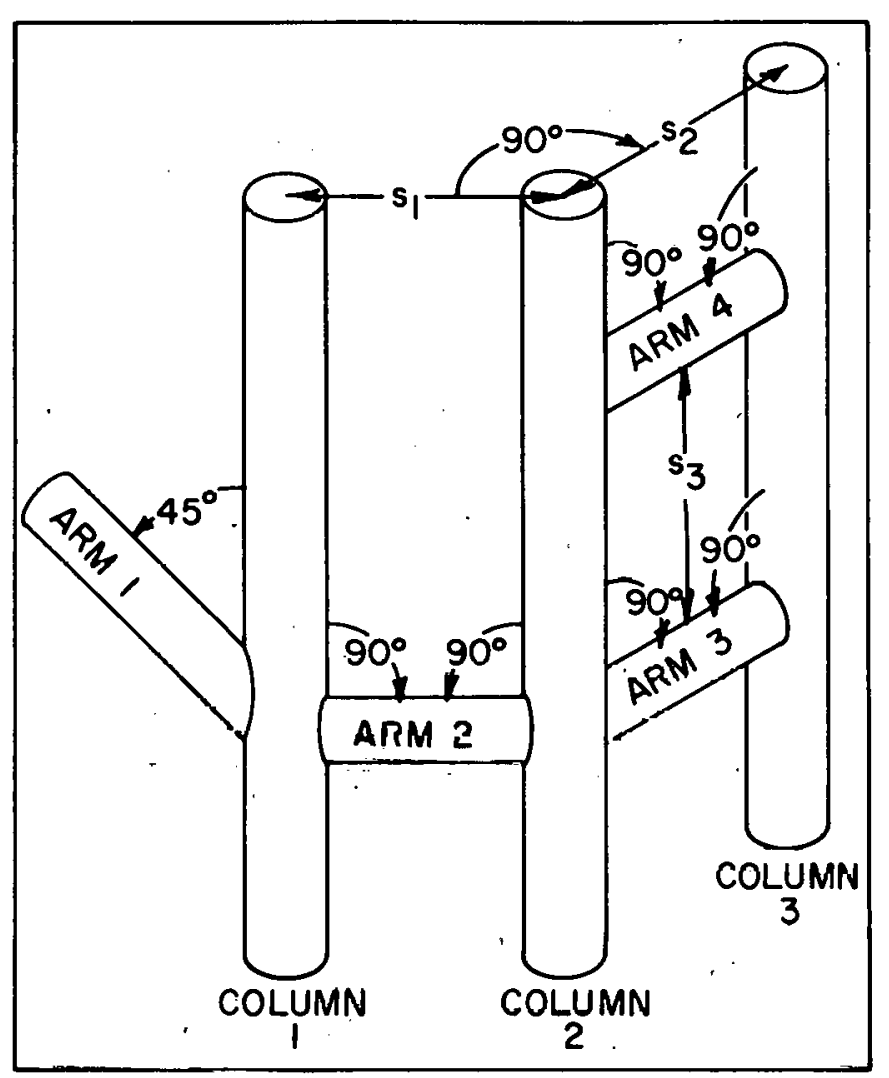

FIGURE 8. Intersecting system with three columns. Permissible pipe diameter's a're calculated iñ Example 2.

Regarding column 2, assume that the distance $s_{3}$ will be chosen so that arms 3 and 4 are in different sectors. Then the sector containing arm 4 uses only one quadränt. Huwever, the scotor cunlaining arms 2 and 3 has two quadrants containiug arms; and hence column 2 is limited to a diameter of 7 inches. Arms 2 and 3 may each be 6.15 inches in diameter (so the previously assigned diameter for arm 2 , relative to column 1 , is allowed to stand). Arm 4, which is permitted 41.28 square inches of intersection area (corresponding to a. diameter of 7.25 inches), can be only 7 inches in diameter, since the arm diameter cannot be larger thai the column diameter.

Finally, column 3 has two sectors to consider, each of which contains only one arm. Ilence, column 3 may have a diameter of 7.25 inches. Arms 3 and 4 are also permitted 7.25-inch diameters, so the smaller diameters already assigned also satisfy the safety criteria for column 3 . 
Setting $s_{3}=11.85$ inches puts arms 3 and 4 in separate sectors. The calculated keff for this system, using the diameters previously assigned, is $k_{e f f}=0.852 \pm 0.018$.

Example 3 (see Figure 9): For this example, the column diameter is allowed to vary. Consider first the sector containing arm 1 . Only one quadrant is used, so $\mathrm{d}_{1}=\mathrm{d}_{2}=7.25$ inches.

Next, the sector containing arms 2 and 3 uses two quadrants, and the maximum column diameter is $d_{3}=7.0$ inches. For the arms, $d_{4}=6.15$ inches and $d_{5}=5.17$ inches (by the same calculations used for arms 1 and 2 of Example 2).

The distance $s_{2}$ must be chosen so that the 7.25-inch part of the column cannot be placed in the same sector with arms 2 and 3 . This is prevented by setting $s_{2}=18$ inches. There is no restriction on $s_{1}$, since the choice of $s_{2}$ is sufficient to put arm 1 in a separate sector from the one containing arms 2 and 3 .

In order to check the conservatism of the GAI model, two O5R calculations were done for this example. With all diameters and spacings as calculated, and with $s_{1} \cong 0.2$ inches, $k_{e f f}=0.833 \pm 0.017$. For $s_{1} \cong 18$ inches, $k_{\text {eff }}=0.821 \pm 0.016$.

\section{COMPARISON OF GEC AND GAI MODELS}

Two different types of comparisons are to be made: (1) ranges of applicability of each model, and (2) maximum arm and column diameters allowed by each model.

The GAI model, using only the data presented in Table III, applies to highly enriched (90 percent uranium 235) uranyl nitrate solution in the minimum critical volume region. The GAI model can, however, be applied to other fisstle materials if corresponding data are obtained for Table III. The general rules are the same in each case. The GEC model can be applied to any fissile solution for which a critical H-to-D curve is available. The GAI model is the first model to allow more than one central column, but the same calculations upon which the GAI model' is based also apply to the GEC model. 


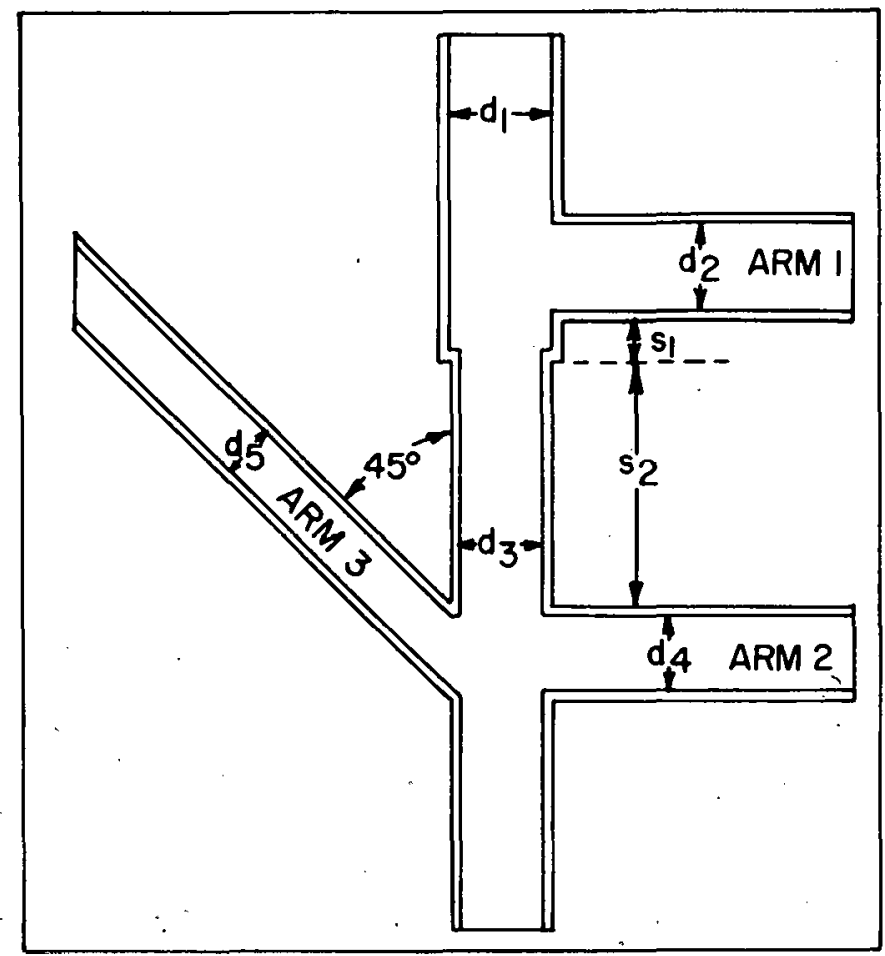

FIGURE 9. Pipe system with a central column of variable diameter. See Example 3 for calculation of safe dimensions.

When applied to uranyl nitrate solution, the GAI model generally allows much larger diameters than the GEC model. Exceptions may occur in the case of a quadrant containing several arms, since the GAI model makes the over-conservative rule that the total allowable area is to be divided among the various arms (see Example 1, results for arms 1. through 6 ).

\section{CONCLUSIONS}

One of the basic simplifying assumptions of the GAI model and others ${ }^{\beta}$ is that an evaluation of the safety of a complex pipe system can be broken down into the study of a number of, smaller parts. If each of these parts satisfies the safety criteria, the entire system is also safe.

\section{${ }^{6}$ RFP-1 499. Loc.cit.}


The concept of the GAI model can be applied to solution systems other than uranyl nitrate if appropriate calculations or experiments are performed. For example, these other systems could include plutonium, uranium 233, or low-enrichment uranium solutions. The rules of the model are exactly as given here; only the numerical values given in Table III would need to be revised.

A second possible variation of the GAI model concerns the particular column diameters and corresponding intersection areas given in Table III. If, for example, one did not need column diameters as large as those given in Table III but needed instead larger intersection areas, one could make such modifications if appropriate calculations or experiments were performed to support these changes. However, the basic assumptions of the GAI model would still apply.

The authors suggest that, whenever possible, proposed pipe systems for fissile solution be evaluated using both the GEC and the GAI models. Since both models are adequately conservative, one can choose the model which gives the better result in each particular case. 